\title{
Correction to: Sexual Behaviors and Health Practices Among Student Service Members and Veterans
}

\author{
David L. Albright ${ }^{1} \cdot$ Antoinette M. Landor $^{2} \cdot$ Justin T. McDaniel $^{3} \cdot$ Kelli Godfrey $^{1} \cdot$ Kari L. Fletcher $^{4} \cdot$ Kate H. Thomas $^{5}$. \\ Jessica Bertram ${ }^{1}$
}

Published online: 8 April 2019

(c) Springer Science+Business Media, LLC, part of Springer Nature 2019

\section{Correction to: Archives of Sexual Behavior https://doi.org/10.1007/s10508-018-1331-3}

Please note that the middle initial of coauthor Antoinette M. Landor was given incorrectly (as "A.") in this article as originally published.

The original article has been corrected.

Publisher's Note Springer Nature remains neutral with regard to jurisdictional claims in published maps and institutional affiliations.

The original article can be found online at https://doi.org/10.1007/ s10508-018-1331-3.

David L. Albright

dlalbright@ua.edu

1 School of Social Work, University of Alabama, Tuscaloosa, AL 35486, USA

2 Human Development and Family Science, University of Missouri, Columbia, MO, USA

3 Department of Public Health and Recreation Professions, Southern Illinois University, Carbondale, IL, USA

4 School of Social Work, St. Catherine University-University of St. Thomas, Minneapolis, MN, USA

5 Public Health Program, College of Health Sciences, Charleston Southern University, Charleston, SC, USA 